\title{
Corrigendum
}

Ann Rehabil Med 2013;37(5):755

pISSN: 2234-0645 • eISSN: 2234-0653

http://dx.doi.org/10.5535/arm.2013.37.5.755

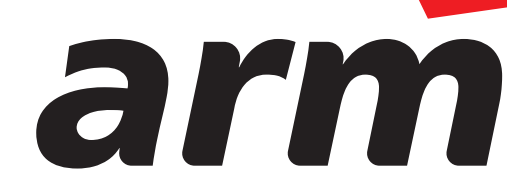

Annals of Rehabilitation Medicine

\section{Correction: Changes in Balancing Ability of Athletes With Chronic Ankle Instability After Foot Orthotics Application and Rehabilitation Exercises}

Hong-Jae Lee, MD${ }^{1}$, Kil-Byung Lim, MD ${ }^{1}$, Tae-Ho Jung, MS ${ }^{2}$, Dug-Young Kim, MD ${ }^{3}$, Kyung-Rok Park, MD ${ }^{1}$

${ }^{1}$ Department of Physical Medicine and Rehabilitation, ${ }^{2}$ Institute of Sports Rehabilitation, Inje University Ilsan Paik Hospital, Goyang; ${ }^{3}$ Department of Rehabilitation Medicine, CHA University College of Medicine, Seoul, Korea

http://dx.doi.org/10.5535/arm.2013.37.4.523

Ann Rehabil Med 2013;37(4):523-533

We found the funding acknowledgment in this article was omitted as published. Additional acknowledgment is as following:

This work was supported by Grant from Inje University 2008.

We apologize for any inconvenience that is may have caused.

Yours sincerely,

Hong-Jae Lee

Corresponding author: Hong-Jae Lee

Department of Physical Medicine and Rehabilitation, Institute of Sports Rehabilitation, Inje University Ilsan Paik Hospital, 170 Juhwa-ro, Ilsanseo-gu, Goyang 411-706, Korea

Tel: +82-31-910-7440, Fax: +82-31-910-7446, E-mail: honglee@paik.ac.kr

(a) This is an open-access article distributed under the terms of the Creative Commons Attribution Non-Commercial License (http://creativecommons.org/ licenses/by-nc/3.0) which permits unrestricted noncommercial use, distribution, and reproduction in any medium, provided the original work is properly cited. Copyright ( 2013 by Korean Academy of Rehabilitation Medicine 